\title{
Professor Kenneth Arrow and Information Systems Frontiers: In memoriam
}

\author{
$\operatorname{Ram}_{\operatorname{Ramesh}^{1}} \cdot$ H. Raghav Rao ${ }^{2}$
}

Published online: 18 March 2017

(C) Springer Science+Business Media New York 2017

It is with great sadness that we announce the passing of Professor Kenneth Arrow, Nobel Laureate and an Advisory Board Member of Information Systems Frontiers. Professor Arrow was a great supporter of Information Systems Frontiers. Incidentally, he was the second person to sign on as an Advisory Board member for Information Systems Frontiers (the first was the late Professor Peter Hammer). Over the years, Professor Arrow contributed both as an Advisor as well as an author to the journal (Arrow 1999; Arrow 2003; Arrow 2012 and Arrow 2015). He was the Advisory Editor for the special issue (Vol. 5, No. 1) on Information Dynamics in the Networked World, Guest Edited by Bernardo Huberman, HP Fellow and Director, HP Laboratories, CA and Prof. John Ledyard, California Institute of Technology, CA.

Dr. Arrow's articles were indeed thought provoking. In (Arrow,1999) he argued that team theory was a suitable method to study distributed processing and formulated a synthesis of decision theory and team theory that included the acquisition of information as an aspect of the formulation. In "Information Dynamics in the Networked World" (Arrow 2003), he pointed out that the internet, while being a means of communicating information in an inexpensive manner, faced the problem of achieving privacy and anonymity. $\mathrm{He}$ further mentioned that markets could be used to motivate and direct the functions of the Internet. In 2012, Arrow (2012) discussed the limited information of economic agents

H. Raghav Rao hr.rao@utsa.edu

Ram Ramesh

rramesh@buffalo.edu

1 University of Buffalo, Buffalo, USA

2 University of Texas at San Antonio, San Antonio, USA and the concept of asymmetric information. He articulated that the distribution of information could not be considered to be a given and information could be acquired at some cost. Information could be considered a commodity with the important characteristic that it was not consumed by being used. Finally in his recent and fascinating "romp through history", Arrow (2015 pg. 9), Dr. Arrow expounded on microeconomics and operations research and how these two disciplines had interacted and touched his life.

Dr. Arrow was the Joan Kenney Professor of Economics (Emeritus) at Stanford University. He received his B.S. from the City College of New York, and M.A. and Ph.D. from Columbia University. In his early years, he served as a weather officer in the United States Army Air Corps and eventually rose to the rank of Captain. Subsequently he spent time as a research associate of the Cowles Commission for Research in Economics at the University of Chicago, where he was Assistant Professor of Economics. At the Cowles Commission, he worked under the guidance of Tjalling Koopmans and Jacob Marschak, and in subsequent years at the RAND Corporation he was exposed to game theory and mathematical programming. His seminal work on social choice and on Pareto efficiency belonged to this period. Subsequently he joined Stanford University and stayed there until 1968, eventually becoming Professor of Economics, Statistics, and Operations Research. At various times during this period, he was a Social Science Research fellow, a Fellow of the Center for Advanced Study in the Behavioral Sciences, Economist with the United States Council of Economic Advisors, Fellow of Churchill College (Cambridge), and Guest Professor, Institute for Advanced Studies, Vienna. In 1968, he was appointed as Professor of Economics at Harvard University. He received the John Bates Clark Medal of 
the American Economic Association in 1957. He was elected as a member of the National Academy of Sciences and the American Philosophical Society. He was a Fellow of the American Academy of Arts and Sciences, the Econometric Society, the Institute of Mathematical Statistics, and the American Statistical Association. He became president of the Econometric Society in 1956 and The Institute of Management Sciences in 1963, and was President-elect of the American Economic Association for 1972. He received the Nobel Prize for Economics in 1972. He did much important work on economic equilibrium analysis, applying the mathematical theory of convex sets and contributed to the theories of growth and decision. His best known work is his analysis of voting processes, Social Choice and Individual Values. His most research interests were in the economics of information and organization, collective decision-making, general equilibrium theory and theories of justice (Arrow 1999). One of his major contributions was in identifying differences of information among economic agents and drawing subsequent economic implications (Arrow 2014).

Rest in peace, Dr. Arrow.

\section{References}

Arrow, K. J. (1999). Team theory and distributed processing: Surprise attack. Information Systems Frontiers, 1(1), 11-14.

Arrow, K. J. (2003). Information dynamics in the networked world. Information Systems Frontiers, 5(1), 5-5.

Arrow, K. J. (2012). Economic theory and the financial crisis. Information Systems Frontiers, 14(5), 967-970.

Arrow, Kenneth, J. (2014). In "Lives of the Laureates", eds. Spencer, Roger and Macpherson, David, Cambridge: MIT Press.

Arrow, K. (2015). Microeconomics and operations research: their interactions and differences. Information Systems Frontiers, 17(1), 3-9.

Dr. Ram Ramesh is Professor of Management Science and Systems at SUNY Buffalo.

Dr. H. Raghav Rao is AT\&T Chair Professor of ISCS in the College of Business, University of Texas at San Antonio. 